\title{
Градуирование и квантификация в современном русском языке
}

\author{
С. М. КОЛЕСНИКОВА \\ Кафедра русского языка, Московский педагогический государственный университет, \\ ул. Малая Пироговская, д. 1, RU-1119992 Москва \\ E-mail: asya28@list.ru \\ (Received: 29 November 2014; accepted: 4 March 2015)
}

\begin{abstract}
Countable words conveying a numeric code and are subject to accountability not quantified explicitly are amenable graduation and become potentially gradable. There are two types of graduation of words: implicitly and explicitly graded words emerging as a result of quantification. The meaning of each lexical unit is implemented in three main areas: graduation, modality, and modal-estimated.
\end{abstract}

Keywords: graduality, quantification, implicitly/explicitly graded words, measure, degree

Исчисляемые слова, передающие «числовой код» и подвергающиеся счету, не являющиеся эксплицитно квантифицированными, поддаются градуированию и становятся потенциально градуируемыми (но не градуированными). Градуирование - это такое определение градуируемого объекта, при котором выявляется (самая) высокая или (самая) низкая степень его признака для градуирующего субъекта, при условии, что градуируемый объект соответствует норме (нулевой ступени измерения), удовлетворяющей градуирующему субъекту (КолесниковА 2010: 31).

Норма традиционно понимается как точка отсчета, соотносится с именами прилагательными обычныци, средний, нормальный, стандартный, посредственный (АрутюновА 1998: 65) и носит субъективно-объективный характер. Данное понятие не является ни абсолютно субъективным, ни абсолютно субъективным. Абсолютная субъективность невозможна потому, что значение, употребляемое говорящим, тогда было бы непонятно собеседнику, так как у каждого их них была бы своя норма (КолесниковА 2010: 58). Не называя представленные явления используемым современными учеными термином «градуальность», лингвисты описали ряд языковых явлений, где числовые выражения градуируются, т. е. выражают значение меры и степени (СЕпиР 1986, БУЛЫГИНА-ШМЕЛЕВ 1988, ЧЕСНОКОВА 1997, КОТВИЦКАЯ 2005, МУСТАЙОКИ 2006, КОЛЕСНИКОВА 2015; ср. ХОВАЛКИНА 1995, РЕПАШИ-СЕКЕЙ 2010 и Др.).

Грамматическая сущность категории числа имеет особенности, не всегда совпадающие с реальным представлением количества (Новиков 1959, МусТАЙоки 2006). Например, слова листва, студенчество, молодежь, мебель имена существительные, собирательные, единственного числа, но реального представления о единичности предмета здесь нет. Следовательно, в русском 
языке есть слова, у которых формы единственного и множественного числа не связаны с реальным значением единичности и множественности. Кроме того, формы единственного и множественного числа могут различаться по значению: хлеб - хлеба́, счёm - счёты. В количественном отношении имен существительных, у которых формы единственного и множественного числа не имеют реальной единичности и множественности, гораздо меньше, чем имен существительных, противопоставленных по числу, поэтому их относят к исключениям (КоЛЕСНиКовА 2015: 67-68).

Категория количества определяется как «достаточно четкая по сравнению с некоторыми другими семантическими категориями», при этом, с одной стороны, различаются точное количество и неточное количество, и с другой абсолютное количество и относительное количество, образующие четыре типа количества: 1) точное абсолютное (В комнату вошли три незнакомых человека /трое мужчин); 2) точное относительное (Двое из нас остались без билета); 3 ) неточное абсолютное (В комнату вошло несколько незнакомых мужчин); 4) неточное относительное (Редко кто из нас способен на это).

Неточному (относительному и абсолютному) количеству соответствуют: а) малое количество (Слушателей на вечер поэзии пришло немного; Торта осталось совсем чуть-чуть); б) нейтральное количество - определенное (Какое-то количество слушателей пришло на вечер поэзии; Несколько ложек еще не хватало на столе) и неопределенное (Табун лошадей бежал по пустыне; Группа людей стояла на остановке автобуса); в) большее количество (Слушателей на вечер поэзии пришло очень много; На ветвях соседнего дерева собралась большая воронья стая).

Слова только и достаточно в высказываниях типа У меня осталось только сто рублей и Денег у меня достаточно определяются как элементы, которые «отражают мнение говорящего о том, какое количество относится к ожидаемому, желательному или нормативному количеству» (МустАйоки 2006: 338).

В лингвистике выделяется два вида градуирования слов в результате квантификации (cp. СЕпиР 1986) - имплицитно и эксплицитно градуированные слова в результате квантификации.

Имплицитно градуированные слова (словосочетания /предложения) в результате квантификации: квантифицированное слово (словосочетание/предложение) семь книг, опираясь на градуаторы «больше, чем»-восемь книг, девять книг и т. д. - и «меньше, чем» - одна книга, две книги... щесть книг, в современном русском языке занимает определенное место в бесконечном ряду квантификаторов (КолЕСНИКовА 1998, КолЕСниКОВА 2010). Отметим, что без квантификации здесь невозможно и градуирование. Градуирование происходит по принципу invelopment - «обертывания» (КолЕСникОВА 1998, КОЛЕСНИКОВА 2010).

Квантифицированные слова (словосочетания/предложения) в результате имплицитного градуирования (имплицитно градуированные квантификаторы): количественные сочетания (числительное + имя существительное и др.) 
занимают определенное место на шкале градаций, опираясь на «больше меньше»: двадцать человек = много людей, где градуирование представляет собой завершенный процесс, результат. При этом много = «больше, чем...». Сравниваемые единицы, например, А и Б, согласно принципу «обертывания», воспринимают неоднозначно: 1) А > Б, т. е. Б, способное быть «обернутым» во множество А; 2) А < Б, т. е. А, способное быть «обернутым» во множество Б $(=\mathrm{Б}>\mathrm{A})>\mathrm{Б}=$ много, а $\mathrm{A}_{1}, \mathrm{~A}_{2} \ldots \mathrm{A}_{\mathrm{n}}<$ Б, что много Б: двадиать Б. 20 является потенциально градуированным; 3) А = Б.

Следовательно, такие слова (словосочетания/предложения), как много / мало людей, большое наследство, бо́льшая часть наследства являются квантифицированными в результате имплицитного градуирования.

Эксплицитно градуированные слова (словосочетания /предложения), но имплицитно квантифицированные (эксплицитно градуированные квантификаторы): выражения типа в этой группе студентов больше, чем в той осуществляют эксплицитное градуирование и подчеркивают сам факт градуирования, а выражения в этой группе много студентов, а в той мало - в этой группе мало студентов, а в той еще меньще передают имплицитное квантифицирующее суждение.

Следовательно, выражение типа больше (меньше) + сущ. в p.n. студентов в современном русском языке является эксплицитно градуированным и имплицитно квантифицированным.

Психологически компаративы в сознании говорящего первичны по отношению к своим абсолютам. Так, выражение больше + cyщ. в $p . n$. первично, а несколько + сущ. в р.п. и много + сущ. в р.n. вторично; хороший $=$ лучше, чем нейтральный, обычный; плохой = хуже, чем нейтральный, обычный. Подобные ряды хороший-лучше : плохой-хуже показывают различные степени сложности с точки зрения логики, психологии и лингвистики.

Субъект градуирования приписывает ту или иную меру (степень) определенному предмету, признаку действию, исходя из определенного состояния сознания человека и общечеловеческих норм объективной реальности.

Градуируемый объект, его характер, у которого определяется та или иная мера (степень) признака, заключается в «соотношении денотативного и концептуального значений» (Ивин 1970: 20).

Семантическая структура слова меньший в современном русском языке представляет собой организацию из четырех (пяти) значений. Единым признаком семем является сема «маленький». Семема 1 является стержневой, отражает психологическую разновидность градуирования и направлена на качественные признаки градуируемого объекта: Самый маленький, где градуатор «самый» подчеркивает обязательную градуальную сему (Из двух зол выбрать меньшее). Семема 2 соотносится с семемой 1 в значениях и передает психологическую разновидность градуирования и характерна для разговорной речи: «то же, что младший» (меньшой сын). Семемы 3, 4 объединяются семой «по меньшей мере». Семема 3 отражает количественный аспект градуирования: «не меньше чем» (занимался по меньщей мере три часа). Семема 4 
реализует психологический и эмоциональный аспекты градуирования: «по крайней мере» (Это, по меньшей мере, странно), где «по меньшей мере» выступает в значении вводного слова; в просторечии передается еще одна семема (5): «самое меньшее» (это мой меньшенький) (о сыне).

Градуаторы меньше/больше употребляются по отношению к градуируемому объекту (КолЕсниковА 1998: 13): «Так привыкли к этаким числам, / что меньше сажени число и не мыслим» (В. Маяковский).

Семантическая структура слова меньше включает в себя три семемы. Основным признаком семем является сема «небольшой».

Семемы слова больше в современном русском языке соответствуют разновидностям градуирования в первом значении слов маленький, мало, мальй. Семема 1: «небольшой по размерам» (маленький рост) - человек маленького роста // Его рост ниже среднего // его рост меньше, чем твой...; «по количеству» (Маленькая группа) $=$ В этой группе меньше людей, чем в той. Семема 2: «немного, недостаточно» (Мало денег = денег меньше, чем достаточно; денег меньше, чем хотелось бы их иметь). Семема 3 (соотносится с семой 1) передает эстетический аспект градуирования, актуализирует свой семантический признак только в высказывании: «то же, что маленький» (= «небольшой по размерам, по количеству»): С мальми потерями // потери были меньше, чем бывают.

Анализ лексического значения слов-градуаторов показывает связь градуирующего субъекта и градуируемого объекта в семантике градуальности, представляющих собой континуум, где нарастание одного компонента вызывает убывание другого. Высокая или низкая степень проявления градуального признака зависит от восприятия градуирующим субъектом качеств градуируемого объекта, что и соответствует лексическому определению градуирования. Рассматривая степени сравнения эксплицитности, Э. Сепир отмечает, что «все слова, поддающиеся количественному выражению чего-либо... заключают в себе градуирование четырех степеней эксплицитности», и дает итоговую картину диапазона градуирования: 1) потенциально градуированные слова или выражения: дом - дома (мн. ч.); 2) слова или выражения имплицитно градуированные в результате квантификации: половина дома... - десять домов; 3) слова или выражения, квантифицированные в результате имплицитного градуирования: большая часть дома; большой дом; много домов; 4) эксплицитно градуированные, но имплицитно квантифицированные слова или выражения: больше (от) дома (чем); больший дом; больше домов (чем) (СЕпиР 1986: 46). Из этого следует, что градуированию подвергаются не выражения языка, а лишь обозначенные этими выражениями черты, признаки, которые могут принадлежать данному элементу действительности и выступать в большей или меньшей степени. Во всей структуре языка Э. Сепир видел градационные отношения (внешнеязыковая функция языковой семантики).

В лингвистике обычно обращается внимание на возможную градацию путем лексем (лексем именного и глагольного характеров). Они могут быть использованы в предикативной функции и для субстантивации предиката. 
Их внутреннее содержание поддается градации и градуированию, например, глаголы с «накопительным» оттенком значения: выражается действие определенной меры - значение меры объекта, возникшего в результате «накопительного» действия (ср. ПАдучЕВА 1996). Данное значение реализуется путем присоединения префикса $н а$ - к производящему слову (глаголу): $3 a$ этот сезон он набегал свыле трехсот километров; Летчик налетал два миллиона километров. Глаголы с таким значением образуются от переходных глаголов, где дополнение может быть выражено градуатором, в данном случае словом с количественным значением - много, массу, уйму и др.: наделать уйму ошибок (или сочетанием с родительным падежом); накупить много вещей.

Являясь градационными словами, наречия меры и степени выполняют функции относительной характеризации признака, которые реализуются в словосочетании, предложении и тексте - объективная характеризация одного явления относительно другого: чуть, несколько, слегка (небольшая степень); гораздо, значительно, куда, много (значительная степень), см., например, «Дневник доктора Борменталя» (М. Булгаков: Собачье сердце) (КолЕсниковА 2010: 132, КолЕСникОВА 2012: 14). На основе своего значения и выполняемой функции низкая степень величины признака выражается наречиями совсем, слегка, немного, чуть (-чуть), едва, еле, несколько, мало, малость (в значении 'немного, чуть-чуть'), почти, совсем (не), вовсе (не) и др.

Лексические единицы слегка, немного, несколько, малость, чуть(-чуть), едва (не), еле(-еле), едва ли не, чуть ли не объединены общей семой «небольшая величина признака», например: «Игроки были изображены с делившимися киями, несколько вывороченными назад руками и косыми ногами, только что сделавшими на воздухе антраша» (Н. Гоголь); «Ка-ра-ул! - еле сльишн воскликнул незнакомец» (И. Ильф, Е. Петров). Наречие несколько употребляется в значении 'немного, чуть-чуть, в некоторой степени' (МАС 2: 479), а еле - 'чуть немного, слегка; едва' (МАС 1: 465). Представленная лексикосемантическая группа имеет собственно градационное значение, сопровождающееся модальными созначениями: выражают незначительный сдвиг по отношению к точке отсчета. Так, немного с семой 'в некоторой степени, мало, слегка', являясь объединяющим компонентом всей лексико-семантической группы, выполняет функцию, заключающуюся в гранд-высказывании, где оно квантифицирует предикативный центр: немного устал [= 'в некоторой степени, слегка'], времени осталось немного [= 'мало'], немного моложе [= 'в некоторой степени'], немного слушается [= 'слегка'], а также содержит сообщение о факте проявления этого признака. Тот факт, что признак проявляется в небольшой степени, составляет добавочное сообщение, которое часто отходит на второй план, где немного используется для смягчения высказывания: «Пока приезжий господин осматривал свою комнату, внесены были его пожитки: прежде всего чемодан из белой кожи, несколько поистасканный [= 'немного, чуть-чуть'], показывавший, что был не в первый раз в дороге. Чемодан внесли кучер Селифан, низенький человек в тулупчике, и лакей Петрушка, малый лет тридцати, в просторном подержанном сюртуке, 
как видно с барского плеча, малый немного суровый [= 'слегка'] на взгляд, с очень крупными губами и носом» (Н. Гоголь).

Особенностью слова немногие является то, что оно свободно передает признак определенности и участвует в квантификации обоих типов. Например: На доклад пришли немногие его друзья - слово немногие дает количественную оценку всему множеству друзей по отношению к предполагаемой количественной норме имеющихся у человека друзей - его немногие друзья = Многочисленные (1); либо может оценивать количественное отношение актуального множества к исходному - немногие его друзья = незначительная часть его друзей (2).

Выбор лексем несколько и немного зависит от дискретности /недискретности градуируемого множества: Он съел (выпил) немного каши (молока) = (выпил) несколько ложек (глотков) каши (молока). Слово несколько градуирует только дискретные множества, в отличие от слов сколько и столько, которые в именительном-винительном падежах могут быть использованы для градуирования недискретных множеств.

Различие употребления слов несколько и некоторые связано с двумя условиями: 1) несколько указывает на то, что референт состоит из неопределенного числа объектов (от 3 до 10 - безотносительно к числу объектов какого-либо «объемлющего» множества); 2) некоторые в количественном значении указывает на то, что референт представляет собой неопределенную часть исходного множества.

Слово немного квантифицирует предикативный признак, выражает собой сообщение о самом факте проявления признака, а то, что признак проявляется в небольшой, некоторой степени, составляет добавочное сообщение: Он немного устал (странный $)=$ «чуть-чуть, слегка» $-[$ Моцарт:] Представь себе... кого бы? Ну хоть меня - немного помоложе; Влюбленного - не слишком, а слегка (А. Пушкин) // немного помоложе = «чуть-чуть, слегка». Ср.: в значении имени числительного немного означает 'небольшое количество' и равно мало: Выпить немного воды. - «Я занят делом весь день и только вечером имею немного свободного времени, чтобы отдохнуть» (А. Островский) // Я имею мало свободного времени.

В тех случаях, когда на немного падает логическое ударение, высказывание становится синонимично высказыванию со словом мало. Если же немного не несет логического ударения, то актуальное членение сходно с актуальным членением предложений, где немного квантифицирует предикативный признак: сообщение о существовании квантифицируемого множества и есть основное сообщение, тогда как существование этого множества в «небольшом количестве» - дополнительное сообщение. Сравним высказывания со словом немного: 1) с ударением на слове - У меня осталось немного денег (сил), где сообщается, что денег (сил) осталось мало; 2) в высказывании без ударения на слове немного сообщается, что деньги (силь) остались, но при этом немного: у меня осталось не много денег (сил). Такое различие выражается и графически: ср. слитное или раздельное написание не. 
Когда немного относится к неисчисляемому имени, смысл высказывания состоит только в сообщении о существовании недискретного (соответствующего) множества; сообщение о том, что множество невелико, может быть не существенным для смысла высказывания. В таких случаях немного имеет значение 'некоторое количество': «Возьмем на радость из моей ладони немного солниа и немного меда» (О. Мандельштам) - здесь слово солнце употреблено как вещественное имя.

Стилевым противочленом к наречию несколько является слово малость со значением 'немного, чуть-чуть': малость утихло, маленько зашибал.

Высказывания со словом мало сообщают, что градуируемое в результате квантификации множество меньше или предикативный признак проявляется в меньшей степени, чем можно было бы ожидать: «Я каждым утром пробужден / Для сладкой неги и свободы: / Читаю мало [= 'немного'], долго сплю» (А. Пушкин). Ср.: как имя числительное мало обозначает 'небольшое количество кого-л. или чего-л.' : «Да ноне мало проезжих» (А. Пушкин) [Как много (сколько) проезжих? - Мало]; «Семейная жизнь доставляла мало удовольствия Степану Аркадьичу» (Л. Толстой) [Как много (сколько) удовольствия? - Мало].

Само существование квантифицируемого множества или предикативного признака является при этом пресуппозицией. Данная особенность актуального членения объясняет и интонационные характеристики предложений со словом мало. Мало обычно несет на себе логическое ударение, хотя коммуникативная роль данного наречия не зависит от интонации. В высказывании У меня мало денег наречие мало употребляется в значении 'недостаточно, меньше, чем нужно'.

Наречие чуть (чуть-чуть) по своему значению тождественно наречиям немного, несколько, малость. Их значения объединяются передачей степени количественного различия признака: немного передает значение 'в некоторой степени; чуть-чуть, слегка’: «Представь себе... кого бы? / Ну хоть меня немного помоложе; / Влюбленного - не слишком, а слегка» (А. Пушкин), а также значения 'незначительный промежуток времени, незначительное расстояние': До города оставалось немного [= 'чуть-чуть, самая малость']; «Я отдохну немного [= 'чуть-чуть, самую малость'] и все пройдет» (И. Тургенев). Употребление немного в роли имени числительного несет значение в небольшом количестве; мало': Bыпить немного воды; «Я занят делом весь день и только вечером имею немного свободного времени, чтобы отдохнуть» (А. Островский).

Анализируемые лексемы разделены на две семантические группы: 1) показатели минимальной степени: чуть, чуть-чуть (лучше, хуже), где слово чуть указывает на наличие минимальной степени признака; 2) показатели небольшой (малой) степени различия: чуть-чуть, немного, несколько (ср. ХОВАЛКИНА 1995).

Наречие немного выполняет градуальные функции сообщения 1) «о существовании с одновременным указанием на небольшое количество» или же 
2) «смягчения» в результате оценивания признака субъектом речи. Данные функции могут быть реализованы и одновременно: Немного пусто в голове, где немного пусто указывает на «впервые называемый признак», на 1) «небольшую его величину» и 2) субъект речи смягчает признак. Синтаксическим коррелятом к слову немного является несколько, употребляемое в книжной речи со значением 'немного, отчасти', 'немного, в некоторой степени'.

Наличие в высказывании слова мало указывает на небольшую степень признака, а слова чуть, чуть-чуть - на наличие признака в самой незначительной степени его проявления, и чуть не сигнализирует о критической точке накопления количества, переходящего в новое качество. Наречие почти выражает такую степень величины, которая воспринимается как величина отрицательная, как некоторое количество одного признака, недостающего для перехода в другой признак. В сочетании со сравнительной степенью много имеет значение 'значительно, в большей степени': много умнее; много красивее; много лучше. Слова много и немало более сходны между собой. В собственно экзистенциальных предложениях слова много и немало свободно употребляются: У него есть немало достоинств; В работе есть много интересных замечаний. Данные слова, находясь в позиции синтаксической безударности, всегда входят в ассертивную часть высказывания (иногда на правах дополнительного утверждения).

Кроме различий, у слов мало - немного и много - немало есть общие черты, отличающие их от их субстантивных и адъективных коррелятов (многие, немногие, мало кто и т. д.): они квантифицируют как дискретные, так и недискретные множества. В результате они выражают количественную оценку безотносительно к исходному множеству. Высказывание Осталось мало денег (сил) указывает на то, что количество денег (сил) невелико по сравнению с ожидавшимися, но безотносительно к общему количеству денег (сил) в универсуме, поэтому словами мало и немного (много) можно дать количественную оценку всему экстенсионалу: Много званных, но мало избранных; Лжей (правд) много, а истина одна; На свете много интересного. Количественная оценка, выражаемая посредством слов мало, много, немного, не является абсолютной. Градуальная оценка представлена по отношению к предполагаемой норме, а не по отношению к исходному множеству. Слова многие, мало кто дают оценку количественного соотношения референта именной группы объемлющего множества: многие (мало кто из...) лингвисты (-ов) разбираются в математике, т. е. в математике разбирается значительная (малая) часть всего множества лингвистов. Сочетания мало какие, мало кто, мало что всегда соответствуют главной реме предложения: «...город еще военный, мало кто вернулся, и те, кто вернулись, тоже думают о войне...» (В. Шкловский).

Таким образом, ключевыми словами, передающими значения средней и достаточной степени, являются понятия меры и степени: в меру, в достаточной степени, в известной мере, умеренно. Наличие архисемы меры и степени в квантификаторах, например, немного, несколько, мало, много и др. 
указывает на их способность вступать в градационные отношения и градуировать семантику предложения-высказывания. Анализируемые в системе современного русского языка лексемы делятся на указатели минимальной степени и небольшой/малой степени. Слова с неопределенно-количественным значением (типа немного) квантифицируют предикативный признак, выражают сообщение не о самом факте проявления этого признака, а то, что признак в небольшой, некоторой степени, составляет добавочное сообщение; предложения-высказывания со словом мало сообщают, что градуируемое в результате квантификации множество меньше: предикативный признак проявляется в небольшой степени. Значение каждой представленной лексической единицы реализуется в трех основных направлениях: градационном, модальном и модально-оценочном. Следовательно, градуированию подвергаются не выражения языка, а лишь обозначенные этими выражениями черты, признаки, которые могут принадлежать данному элементу действительности и выступать в большей или меньшей степени (КолЕСНИКОВА 2015: 102).

\section{Литература}

АРУТЮНОВА 1998 = АРУТЮНОВА Н. Д. Язык и мир человека. Москва: «Языки русской культуры», 1998.

БулыгинА-ШмелЕВ 1988 = БулыгинА Т. В., ШмелЕв А. Д. Механизмы квантификации в русском языке и система количественной оценки. В кн.: Референция и проблемы текстообразования. Москва: «Наука», 1988. 5-18.

Ивин 1970 = Ивин А. А. Основания логики оценок. Москва: «Издательство МГУ», 1970.

КОЛЕСНИКОВА 1998 = КОЛЕСНИКОВА С. М. Семантика градуальности и способы ее выражения в современном русском языке. Москва: «МПУ», 1998.

КОЛЕСНИКОВА 2010 = КоЛЕСНИКОВА С. М. ФУнкиионально-семантическая категория градуальности в современном русском языке. Москва: «Высшая школа», 2010.

КОЛЕСНИКОВА 2012 = КОЛЕСНИКОВА С. М. Синтагматические особенности наречий меры и степени и их градуальная функция в современном русском языке. Becmник Московского областного государственного университета 2012/3: 14-20.

КОЛЕСНИКОВА 2015 = КОЛЕСНИКОВА С. М. Современный русский язык. Морфология. Учебное пособие. Москва: «Юрайт», 2015.

КОТВИЦКАЯ $2005=$ КОтВИЦКАЯ Э. С. Русские числительные в таблицах, комментариях и упражнениях. Сборник упражнений по русскому языку для иностранцев. Москва: «Издательство МГУ», 2005.

МАС = ЕвГеньевА А. П. (ред.) Словарь русского языка. Т. 1-4. Москва: «Русский язык», 1981-1984.

МустАЙОКИ 2006 = МустАйоки А. Теория функиионального синтаксиса. От семантических структур к языковым средствам. Москва, 2006.

Новиков 1959 = Новиков Л. А. Природа числа имен существительных и их стилистические функции. Русский язык в школе 1959/5: 18-21.

ПАДУчеВА 1996 = ПАДУчЕВА Е. В. Семантические исследования. Семантика времени и вида в русском языке. Семантика нарратива. Москва: «Языки русской культуры», 1996. 
РЕПАШИ-СЕКЕЙ 2010 = РЕПАШИ Д., СЕКЕЙ Г. О граДУальности в сопоставитеЛЬном аспекте. Вестник Московского областного государственного университета 2010/5: 110-118.

СЕПиР 1986 = СЕПиР Э. Градуирование. Семантическое исследование. В кн.: Новое в зарубежной лингвистике. Т. 16. Москва, 1986. 43-78.

ХОВАЛКИНА 1995 = ХОВАЛКИНА А. А. Лексическое выражение степени величины признака в современном русском языке. Симферополь: «Таврия», 1995.

ЧЕСНОКОВА 1997 = ЧЕСНОКОВА Л. Д. Имя числительное в современном русском языке. Семантика. Грамматика. Функичи. Ростов-на-Дону, 1997. 